\title{
Managing higher education for a changing regulatory environment
}

Managing higher education

\author{
Colin Scott \\ College of Social Sciences and Law, University College Dublin, Dublin, Ireland
}

\begin{abstract}
Purpose - This article addresses the relationship of universities to their changing regulatory environments internationally.

Design/methodology/approach - This article updates analysis published in 2004 exploring the contrasting modes of, and key trends in, regulation of higher education across eight OECD (Organisation for Economic Co-operation and Development) states. The article offers a wider analysis of the changing patterns of regulation rooted in mutuality, oversight, competition and design, and the implications for the management of higher education institutions.

Findings - Since 2004, higher education has seen more growth in oversight-based and competition-based regulation, but also some decentralization of regulation as an increasing cast of actors, many international and transnational in character, have asserted themselves in key aspects of the regulatory environment. This article explores the implications of these changes in the regulatory mix over higher education for the ways that universities manage their regulatory environment, arguing first, that there is significant evidence of metaregulatory approaches to regulating universities, and second, that such a meta-regulatory approach is consistent with an emphasis on university autonomy, raising a challenge for universities in how to use the autonomy (variable by country) they do have to manage their environment.

Originality/value - This article offers an original analysis of how universities might most appropriately respond, deploying their autonomy, however variable, to address their external regulatory environment. The author suggests we might increasingly see the external regulatory environment as meta-regulatory in character and universities making more use of reflexive governance processes.
\end{abstract}

Keywords Regulation, Higher education, Rankings, OECD

Paper type Research paper

\section{Introduction}

Universities originated as, and maintained themselves as, self-governing communities of scholars, engaging in teaching and scholarship, over many centuries. The expansion of higher education in the twentieth century increasingly involved state support for their missions and a broadening range of policy objectives associated with higher education. A 2004 study found that traditions of regulation based in mutuality or community were increasingly giving way to more oversight and more competition in the steering of higher education by governments. Since 2004 higher education has seen more growth in oversightbased and competition-based regulation but also decentralized state regulation as an increasing cast of actors, many international and transnational in character, have asserted

(C) Colin Scott. Published in Public Administration and Policy. Published by Emerald Publishing Limited. This article is published under the Creative Commons Attribution (CC BY 4.0) license. Anyone may reproduce, distribute, translate and create derivative works of this article (for both commercial and noncommercial purposes), subject to full attribution to the original publication and authors. The full terms of this license may be seen at http://creativecommons.org/licences/by/4.0/legalcode

This article originated as the keynote at the International Conference on Global Regulatory Governance hosted by the Chinese University of Hong Kong in July 2019. I thank the organisers and in particular Professor Carlos Lo Wing-Hung for the great honour of being asked to address this conference in my role as Convenor of the ECPR Standing Group on Regulatory Governance. I am grateful also to Slobodan Tomic and participants in a seminar held at Oxford University Centre for Socio-Legal Studies in May 2019 for comments on an earlier draft.

Received 5 October 2020 Revised 18 January 2021 Accepted 25 January 2021
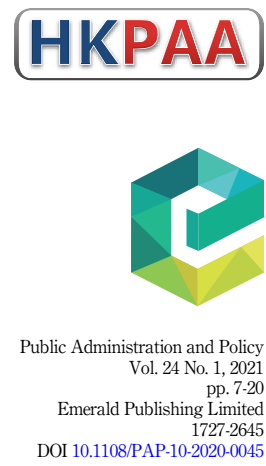
PAP

24,1

8

themselves as key aspects of the regulatory environment. Regulation as a concept is drawn broadly in the regulatory governance scholarship, drawing from a mix of modes of control extending from the traditional hierarchy of rules to bring in competitive processes, community-based controls, and regulation through design.

This article explores the implications of this change in the regulatory mix of higher education and the ways universities manage their regulatory environment. My own work combines the perspective of the regulatory scholar with the experience of a practitioner in university governance. The article is largely conceptual rather than empirical. It links the changing regulatory environment of higher education to the development of governance machinery and the norms within universities in a context where universities increasingly participate in and learn from international networks, both of universities and of regulatory bodies.

Some researchers see risks of hyper-regulation and excessive competition in steering universities, driven by changes in governance associated with New Public Management (NPM) and ideologies of neo-liberalism (Olssen and Peters, 2005). The author argues that such understandings of change, whilst reflecting both reductions in public funding in many countries and increasing market pressures on universities, especially linked to internationalisation, tend to underplay the role of university autonomy. The author strongly suggests thinking of higher education's regulatory environment not as wholly directive, but rather as meta-regulatory in character - acting to steer the self-regulatory capacity and (variable) autonomy of universities. For universities this suggests that they use their autonomy to develop their internal management in a variety of modes to suit their objectives and the modes of control they face, involving more reflexive processes to govern and to animate their purposes and missions. Emphasising the purpose and values of autonomous universities does not deny the need for them to account for their public role and state funding. However it does reassert the role of universities as principals in defining their missions, recasting the army of external regulators as agents in supporting universities to fulfil their roles, as much as they are principals setting public policy agendas independent of higher education institutions.

\section{Transforming and regulating higher education}

Universities originated as self-governing communities of scholars and students which can trace their history back to antiquity in Asia, Africa and Europe (Marginson, 2011). The ideals of university autonomy originate from a time when universities were small, elite communities of scholars offering higher education only to a small proportion of national populations and were, accordingly, at the margins of the concerns of emergent state governing apparatus, whilst they nevertheless held some significance for state formation. As state capacity, generally, grew, the changing role and scale of universities in the twentieth century created a challenge both for the institutions and for the governments which, in most countries, took on a significant degree of the funding responsibility for a much expanded and diversified higher education sector with varying degrees of institutional autonomy (Scott, 2011). The transformation of the state's relationship to higher education in the twentieth century focused on the quality of, and accessibility of, higher education and also the importance of knowledge development through research and innovation (OECD, 2009).

Once universities are seen as instruments of public policy, increasingly attracting public funds either directly (through grants) or indirectly (for example through state loans to cover student fees), then it is inevitable that governments will take an interest in understanding their activities and steering their actions and outcomes towards demonstrating value for money in achieving not only institutional but also national goals. As the massification of higher education in many industrialized countries in the post-Second World War period made 
higher education institutions increasingly dependent on state funding, so they became intimately linked both to the constraints and ideas of the wider state machinery. Thus when the fiscal crisis of the 1970s brought the expansion of the welfare state to a halt in many European countries, the expanding scope and cost of higher education came into question. Fiscal pressures on states to ensure value for money in higher education have, if anything, increased, not least due to the global financial crisis of 2008 (Hazelkorn, 2011), and the COVID-19 pandemic of 2020 (which has affected, amongst other things, global student mobility, and thus fee income).

Higher education governance has shifted from funding-based instruments to a more identifiably regulatory mode of governance, in terms of government oversight (Black et al., 2015). Notwithstanding this increased state scrutiny, patterns of globalization and increasing competition have generated a more complex regulatory space for higher education in which national governments are less able to fully set agendas. The remarkable growth in international student mobility has been, for some countries, a source of additional income to support growth in higher education. The United States is the largest recipient of overseas students and saw growth of more than 70 percent in international student numbers between 1999 and 2013, from 450,000 to 785,000. UK policies during this period drove British universities to similar growth in international student numbers, 232,000 in 1999 to 416,000. Australia more than doubled its international student numbers, to 250,000 in the same period. While France saw significant growth in international student numbers in the early 2000s, nearly doubling numbers between 1999 and 2006 to nearly 250,000, the growth did not continue and numbers fell somewhat in the period to 2013. Germany has seen only 10 per cent growth in international student numbers between 1999 and 2013, with close to 200,000 international students. Whereas Germany once ranked $3^{\text {rd }}$ in the world for receiving international students, by 2013 it only ranked $5^{\text {th }}$. By 2013 the other countries ranking in the top ten international student destinations were Canada, Japan, China, Italy and Austria, with the top ten receiving more than 2.4 million international students between them, whereas the top ten receivers took only 1.3 million students in 1999 . The largest country of origin for international students by far is China, at over 700,000 students in 2013, more than the next four countries (India, Germany, South Korea, and France) combined (Choudaha, 2017).

Government interest in higher education has sought to diversify the sector so as to provide advanced education both of more applied and more academic varieties across a range of different kinds of higher education institutions (in addition to the self-governing universities), frequently with significant distinctions between the type of providers involved (Shattock, 2008). Governments have also sought to diversify those who benefit from higher education, with emphasis on recruiting larger numbers from historically underrepresented socioeconomic categories. With research, governments have increasingly become preoccupied with justifying significant public expenditure through evidence both of competitiveness and impact.

The emergent regulatory landscape of national state regulation was traced in a 2004 comparative study of higher education regulations in eight OECD member states. The study found that traditions of regulation based on principles of mutuality or community-based governance were being supplemented or displaced by a growing emphasis on hierarchy and competition in the oversight of universities (Hood et al., 2004). In the 2004 study we noted that all four basic types of control - as mutuality, contrived randomness, competition and oversight - could be found within the organization and regulation of behaviours in higher education. Mutuality was found in peer-review processes in research and promotions; contrived randomness was found in 'garbage can' committee procedures and unpredictable regulatory decisions; competition was found in the rivalry for prizes, research claims, grant capture, budget share and grant funding; and oversight was found in government reporting

Managing higher education 
PAP

24,1

10

requirements and, for some countries, the approval of curriculum and appointments (Hood et al., 2004, pp. 75-77).

For the contrasting patterns of higher education regulation in 2004 it was significant whether higher education institutions were regarded as part of the central or regional state apparatus (as in Germany and France, for example), as this entailed state oversight over such matters as senior academic appointments and pay, or whether they had emerged as largely autonomous bodies (as with the UK and Australia), albeit with significant state funding. The United States and Japan have placed much larger emphasis on private universities, albeit with significant growth in state universities in the United States. Even where universities are private, as with significant portions of the US, Japanese and to a lesser extent German systems, state funding of educational grants and or loans may give the state a significant interest in educational and research outcomes. We also found considerable evidence of a mixture of the four basic forms of control, with quality assurance increasingly combining the mutuality of peer review with the oversight of more hierarchical reporting requirements (Hood et al., 2004).

The comparative research on higher education regulations found a somewhat different mixture of technique across eight OECD member states (Table 1). Within most systems a focus on mutuality-based governance was identified, reflecting strong traditions of university autonomy (not always extending to other kinds of higher education institutions). The UK shifted from a tradition of mutuality, to a degree, to growing patterns of oversight-based hyper-regulation over universities. The trend towards more oversight-based regulation was widely observed, coupled with a growing trend for more competitive modes, frequently from a low base. At that time only the US was identified as having a low level of oversight-based regulation. But the US system, at that time, saw a much higher dependence on competition for steering, with other countries having low, but in many cases, increasing dependence on competition. Evidence of contrived randomness at play was limited.

We found also that trends in forms of control tend to be related, with the ratcheting of one mode accompanied by the loosening of another, which we referred to as 'the mirror image hypothesis'. For example, in some European systems, an increase in competition saw a reduced emphasis on state controls over appointments and salaries. In Australia, an increased mutuality in quality assurance saw a reduction in the oversight mechanism of mandatory reporting. As in the UK, sometimes modes of control grew together ('the double

\begin{tabular}{|c|c|c|c|}
\hline $\begin{array}{l}\text { Intensity of Governance } \\
\text { Governance Mode }\end{array}$ & Low & Medium & High \\
\hline \multicolumn{2}{|l|}{ Mutuality } & US, UK & \multirow[t]{2}{*}{$\begin{array}{l}\text { Australia, France, } \\
\text { Germany, Norway, } \\
\text { Japan, Netherlands }\end{array}$} \\
\hline Oversight & US & $\begin{array}{l}\text { Australia, France, } \\
\text { Germany, Norway, } \\
\text { Japan, Netherlands, UK }\end{array}$ & \\
\hline Competition & $\begin{array}{l}\text { France, Germany, } \\
\text { Norway, Japan, } \\
\text { Netherlands }\end{array}$ & Australia, UK & \multirow[t]{3}{*}{ US } \\
\hline $\begin{array}{l}\text { Contrived } \\
\text { Randomness }\end{array}$ & $\begin{array}{l}\text { Australia, France, } \\
\text { Germany, Norway, } \\
\text { Japan, Netherlands, US }\end{array}$ & UK & \\
\hline Source: Adapted from Hoo & et al. $(2004$, p. 82 , Table 3.3 & & \\
\hline
\end{tabular}

Table 1.

Regulating Higher Education: Eight OECD member states in 2003 
whammy'), as with increased competition accompanied by an increase in central oversight (Hood et al., 2004). Writing in 2004 we observed the growing importance of university rankings generated by private organizations, mainly media companies at that time (Hood et al., 2004).

Managing higher education

\section{Regulating higher education today}

The trends evident in the regulation of higher education in 2004 have continued in the period since. Notably traditions of self-governance and mutuality have come under challenge from greater oversight and greater competition in national, transnational and international governance. Fragmentation in regulation has been accompanied by a shift towards more oversight and more competition steering the higher education sector. Rankings bodies, comprising a mixture of private, sectoral and governmental organizations, implicitly point to norms that higher education institutions need to follow to be highly ranked. This is linked to the commercial motivations of the ranking body and/or their own sense of the priorities for the sector (Hazelkorn, 2011). There has been significant growth in international student mobility, as noted above, creating market pressures to demonstrate reputation and high rankings and with increasing investments in creating internationally competitive higher education institutions, both in European countries such as Germany and France and in Asia, for example in China, Hong Kong and Singapore. Higher education regulation shows a degree of decentering as other nodes and models of regulatory governance have taken on greater significance (Black, 2001) and knowledge, education and research have become ever more globalized. In the next sections the author addresses the fragmentation of higher education regulation in terms of who is engaging in regulation, over what values or objectives is regulation taking place, and what mix of modes or instruments of regulation is being deployed.

\section{Who regulates?}

The diversification of higher education institutions beyond the traditional self-regulating community of scholars and the increasing interest of the state, combined with the proliferation of competitive forms of steering, such as rankings, has vastly increased the cast of actors within the higher education regulatory space. Today key actors include:

- government departments and specialised state agencies (including funding bodies and quality overseers)

- national private regulators (including private professional accreditors and selfregulatory university consortia such as the transnational AdvanceHE)

- a range of supranational bodies, especially within the EU, but also including the monitoring functions of the OECD and UNESCO and intergovernmental networks such as the European Association for Quality Assurance in Higher Education (ENQA) and the International Network for Quality Assurance Agencies in Higher Education (INQAAHE) (Dill, 2011)

- a range of transnational private regulators including the media and consultancy organisations who organise some of the university rankings schemes, and the emergent associations of higher education institutions whose research and advocacy activities can increasingly be seen as part of the steering mechanisms over higher education (Dill, 2011). International networks both of regulators and of universities are in part a response to inter-governmental actions to set higher education norms, but they also permit both regulators and universities to detach themselves, to a degree, from the states where they are located. 
PAP

24,1

What values?

Historically the self-regulating community model for universities gave priority to teaching and learning and, subsequently, advancing research. To a varying degree, these were key values around which self-regulation was organised.

We have seen that as mass higher education has developed, for national governments who are providing much of the funding, it is increasingly important for universities to demonstrate their value for money, a key part of the "audit explosion" in the public sector (Shore and Wright, 2000). In public audit doctrine, value for money considers economy, effectiveness and efficiency and goes beyond the more traditional (but still important) audit doctrines of ensuring that the money was spent for the purposes for which it was allocated (Bowerman et al., 2003).

Beyond the value for money, higher education is a major source of social mobility and a key tool for enhancing life opportunities for those from disadvantaged backgrounds. Concerns with increasing and widening participation in higher education are increasingly allied with wider commitments to removing barriers to equality for both students and staff at universities as demonstrated by equality legislation (for example addressing gender, disability, race, sexual orientation), and beyond formal equality, to achieve deeper cultural change. The strong focus on one set of values, such as gender equality, risks ignoring or downplaying other equality objectives, such as seeking to eliminate racism (Bhopal and Henderson, 2019).

\section{How is regulation carried out?}

Regulation of higher education in 2020 has a varying mix of mutuality, competition and oversight. In some systems, mutuality is perceived to be under threat with a more limited role for design-based control generally. The role of mutuality today is frequently located within a wider hierarchical structure under which oversight requires processes to be undertaken. For example, peer review constitutes a significant proportion of the activity in the realm of quality. Higher education has always had a transnational or global dimension as mobility of people and ideas has been an essential aspect in both generating and sharing knowledge (Marginson, 2011). Transnational mobility is now accompanied by various forms of transnational oversight and, with that, steering the behaviour of institutions towards some desiderata and away from others, distinct from national government policies and oversight.

Increasing oversight-based mechanisms in higher education involve the setting, monitoring and enforcing of rules. The framework norms for higher education tend to be set through legislation. Such rules are also incorporated into authorisation mechanisms (for example setting down the minimum requirements for recognition as a university in many countries), and within funding mechanisms within which compliance with norms is a condition for grant of funding. Hierarchy is a central aspect of controls which seek to manage the number of students in higher education, which are a core part of some more managed systems (seeking to control public expenditure) but less significant in systems where student fees and loans are more significant. Facing continuing financial pressures in the 2008 global financial crisis and now in the 2020 coronavirus pandemic governments have tended to increase oversight of value for money in higher education. In some cases, such as the UK and Australia, governments engage state agencies directly with assessing the quality of education and the impact of research. Quality has also been central to the growth in supranational oversight of higher education, especially in the EU. The European Network of Quality Assurance in Higher Education (ENQA) (Enders and Westerheijden, 2011) has moved beyond its inter-governmental origins and transformed into an association and de facto standard setter for quality assurance processes in Europe, engaging in the review of national quality assurance agencies and with an increasing global reach (Dill, 2011). 
Increasing competitive pressures have arisen from national policies in some countries, but there has been even more competition for international students and staff due to the presence and significance of university rankings. The transition towards more data-driven oversight is a core component of the competitive approach to regulation involved with scoreboards and rankings, developed by both public and private organisations. There has been an increasing emphasis on research selectivity, seeking to channel state research block grant funding to higher education institutions (HEIs) best able to demonstrate high quality. There has also been a shift from block grants to competitive grants. Within the EU the latter shift has been amplified by the emergence of substantial EU funding for research projects on a competitive basis.

A core competitive pressure which has intensified over recent years stems from the growth of numerous subject-based and institutional rankings of higher education both nationally and internationally. Whereas the 2004 study noted key business school and national university rankings, 2004 turned out to be an inflection point, with the launch of a number of global institutional rankings, first by Shanghai Jiao Tong University in 2003 (now referred to as the Academic Ranking of World Universities) and then by Times Higher Education in cooperation with Quacquarelli-Symonds (QS) in 2004 (Hazelkorn, 2011). Times Higher and QS subsequently parted company in 2010, leading to competition between the quite similarly framed but distinct rankings of Times Higher and QS. These three influential sets of rankings, ARWU, Times Higher and QS, have generated significant concern both in higher education and with governments because they are partial and oriented to data that is available. First, there is an incomplete picture of quality and second it gives institutions an incentive to change practices in order to enhance their position in the rankings and thus in competitive markets for reputation, students, staff, etc., whether or not this advances or possibly undermines their institutional mission (Hazelkorn, 2011). The European Commission responded to the limitations of extant rankings systems in 2014 with the establishment of U-Multirank, a system to compare universities across core criteria that enables the user to select which criteria to compare and in a way which avoids simple numerical rankings. Recognising the credibility challenges of ranking systems, their originators have established their own meta-regulatory oversight in the form of the IREG Observatory on Academic Ranking and Excellence, an international non-governmental organisation made up of rankings experts which, with the support of UNESCO, has established a set of principles for rankings processes (the Berlin Principles, adopted in 2006) (Dill, 2011).

Whilst mutuality-based collegial governance clearly remains of importance in the regulation of higher education, it is clear that hierarchy and competition have become increasingly significant bases of control. There is not much evidence of the different forms of design-based regulation taking hold in higher education regulation.

\section{University autonomy and meta-regulation of higher education}

Regulation of higher education in many countries places considerable emphasis on preserving and even enhancing the organizational autonomy of universities for varied reasons including perceptions that autonomy is a foundation for strong performance. There are also democratic grounds for advancing autonomous universities as important nodes of independent knowledge and learning within democratic states. Even within Western Europe the autonomy of universities is highly varied, with French universities generally having low autonomy when it comes to key organizational decisions, while English universities experiences the greatest autonomy (Boer and Enders, 2017). The rapidly changing external environment of regulation risks compromising university autonomy, however variable that autonomy may be across different countries. Many see significant changes in universities

\section{Managing higher education}


PAP

24,1

14

themselves towards centralization, neo-liberalism and managerialism, as universities have apparently bent to the dictates of new public management (Olssen and Peters, 2005), though this claim can be contested.

The European Universities Association (EUA) has underpinned its efforts to protect university autonomy with the development of a tool for assessing variation in university autonomy in European countries, with reference to organizational, financial, staffing and academic matters. Across these four dimensions there are a total of 38 indicators (Table 2).

The EUA finds a high degree of variation in the degree of university autonomy in Europe. Amongst the group within the 2004 study, higher education institutions in France have traditionally been treated like civil service bodies and, in 2017, were rated as having low academic autonomy (for example admissions and curriculum content), and medium-low autonomy in respect of staffing, finance organization, notwithstanding a strong government commitment to enhancing university autonomy (Lodge, 2018). Intriguingly, whilst the Netherlands rates medium to high on organizational, financial and staffing autonomy, it rates medium-low on academic autonomy, which reflects a higher degree of centralized oversight of programme accreditation. Notwithstanding the trend towards hyper-regulation of higher education, the UK remains an exemplar of university autonomy, according to the EUA, with the sector scoring high for all four sets of autonomy criteria, notwithstanding the growth of centralized government agency oversight (Shattock and Horvath, 2019).

How can the growing intensity of different forms of regulation be reconciled with both the traditional autonomy and the renewed autonomy claims of universities? One possible approach is to recognize evidence that higher education regulation frequently draws on the self-regulating capacity of universities and to suggest that meta-regulation, the steering of self-regulatory capacity (Parker, 2002), may be a positive way to think about the relationship between universities and their regulatory environment. Meta-regulation involves a requirement on the regulatee to do something, but without specifying what they should do, with some form of feedback around what is done in response to the requirement to act (Parker and Braithwaite, 2003). Whilst meta-regulation was conceived to link state hierarchy to self-regulatory capacity, we can see meta-regulatory pressure coming from other sources too, including competition and community activities (Scott, 2008). Notably, the ratcheting of international competition for prestige, students and research funding is mediated in part through the diverse range of rankings. The rankings organisations select their own criteria for evaluation (with considerable variation between them) but do not have authority to direct

\begin{tabular}{|c|c|c|c|}
\hline Organisational & Financial & Staffing & Academic \\
\hline Selection Procedure/Criteria & Length/Type of Public & Staff Recruitment & Deciding on Overall Student \\
\hline for Rector & Funding & Procedures & Numbers \\
\hline $\begin{array}{l}\text { Dismissal/Term of Office of } \\
\text { Rector }\end{array}$ & Keeping a Surplus & Staff Salaries & Selecting Students \\
\hline Inclusion/Selection of & Borrowing Money & Staff Dismissals & Introducing/Terminating \\
\hline External Members in & & & Programmes \\
\hline Governing Bodies & & & \\
\hline Deciding on Academic & Owning Buildings & \multirow[t]{7}{*}{ Staff Promotions } & Choosing Language of \\
\hline Structures & & & Instruction \\
\hline \multirow[t]{5}{*}{ Creating Legal Entities } & Charging Tuition Fees & & Selecting QA \\
\hline & \multirow{2}{*}{\multicolumn{2}{|c|}{$\begin{array}{l}\text { for National/EU } \\
\text { Students }\end{array}$}} & \\
\hline & & & \\
\hline & \multirow{2}{*}{$\begin{array}{l}\text { Charging Tuition Fees } \\
\text { for Non-EU Students }\end{array}$} & & Designing Content of \\
\hline & & & Programmes \\
\hline
\end{tabular}

Table 2.

Parameters of university autonomy

\footnotetext{
Source: Adapted from Pruvot and Estermann (2017, p. 14)
} 
institutions what to do. Thus there is no hierarchy in these mechanisms. Rather HEIs must navigate expected costs and benefits of rankings and make decisions as to any response they might make to external stimuli. Universities retain autonomy in their response to rankings, but also take feedback from rankings, thus constituting a form of meta-regulatory steering.

Higher education yields a number of very significant examples of meta-regulation which are underpinned, variously, by hierarchy, competition and community at both national and transnational levels. Because of their claims to autonomy we should not be surprised that meta-regulation has proved to be important in higher education and that it draws on these wider bases of competition and community. Indeed, the operation of important metaregulatory regimes over higher education in England and Wales tends to challenge claims of a hyper-regulatory environment (Shattock and Horvath, 2019). Or if it is hyper-regulatory it is, to some degree, hyper- and meta-regulatory at the same time.

Table 3 provides examples of meta-regulatory regimes over higher education based on the different modes of control. Hierarchy-based meta-regulation is exemplified by processes of strategic dialogue, seen in Hong Kong and Ireland, which require HEIs to engage in a process of setting down and discussing with regulators their objectives and proposed outcomes in respect of their core missions, which indicates how they contribute to some, but not necessarily all, government-determined sectoral policy objectives. The content of the performance documents is for the HEIs to determine, but with steering from and accountability to the regulator. Through this mechanism formal institutional autonomy is substantially preserved but the funding agency is able to nudge HEIs towards more ambitious targets in respect of national goals. The process in Ireland involves a degree of mutuality since external assessors in the dialogue process are drawn from overseas HEIs.

A community-based approach is exemplified by the Athena Swan Charter programme in the UK, Australia and Ireland under which HEIs volunteer to review both organizational and department level policies/achievement with respect to gender equality and to devise action plans to remove barriers to equality. Appropriate standards accreditation is given where analysis and plans meet (Ovseiko et al., 2017) and accreditation under Athena Swan is a mark of pride and also a source of encouragement within organizations.

Rankings provide a clear example of a competition-based meta-regulatory approach in the sense that rankings bodies have no capacity to require HEI actions. Whether admitted or not, HEIs do engage with rankings in ways that seek to enhance their positions. In the case of the recently introduced Times Higher Social Impact Rankings, the normative content is not simply about the core mission of research and education, but rather about engaging with and advancing the UN Sustainable Development Goals. This includes values extending beyond climate action to combat gender and wider inequality, promote health and well-being, and support sustainable consumption and sustainable cities. No university is required to engage with these Global Goals, but those that do are rewarded in rankings, and the submission process is quite normative in steering universities towards

\begin{tabular}{llll}
\hline Control Base & Examples & Jurisdictions & Values/Objectives \\
\hline Hierarchy & Strategic Dialogue & Ireland, Hong Kong & VFM, Effectiveness \\
Community & Athena Swan & UK, Australia, Ireland & Equality \\
Competition & Times Higher Impact Rankings & Transnational & Sustainability \\
& Student Surveys & Netherlands, UK, Australia, Ireland & Quality \\
Hybrid & Quality Assurance & Australia, UK, & Quality
\end{tabular}

Source: Author's own research

Managing higher education 
PAP

24,1

particular forms of engagement with and governance of the global goals within their organizations.

In respect of quality regimes, and certain other matters in some countries, it is increasingly common to find governments using oversight measures to require certain actions to be taken, but leaving the definition of those actions to the institutions themselves, subject to a degree of scrutiny that often involves peer review. Thus, oversight is combined with the mutualitybased regimes of self-assessment. Traditional mutuality-based quality assurance processes are increasingly supplemented by student surveys, which can be linked both to funding mechanisms and to rankings. This has been the case in the UK, Netherlands, Australia and Ireland, which thus introduced competition-based steering. Within such systems students are increasingly characterised as consumers with collective power to regulate HEIs, thereby linking the market to the student survey outcomes. Such surveys may then constitute part of systems of rankings.

\section{Managing the regulatory environment in universities}

The enhanced role of the state in shaping higher education policies has been underpinning a shift towards strategic planning in higher education institutions. This shift, along with the related management structures for implementation, have created the context in which governments have supported the institutional objectives and have also created the posture within higher education institutions with which they wish to respond to external steering stimuli (Shattock, 2010). Higher education regulation is not simply a matter of compliance with externally determined norms. (Braithwaite et al., 2004). To attain autonomy, do universities need to determine for themselves their missions and the norms which will guide their work internally, with academic staff protected by academic freedom to determine their research plans and the content and style of their teaching? If this is correct, then institutions' autonomy and academic freedom cannot be without accountability. But the need for accountability need not imply that universities must manage themselves simply to comply with external reform requirements, nor that a single management mode should be deployed. Indeed, Peter Maasen has set down the university governance paradox "the more university leaders take on and operate in line with the reform agenda's ideologies, the less effective they appear to be in realising some of the reform intentions" (Maassen, 2017, p. 290).

For activities which are substantially governed by relatively stable community or collegial norms, some form of mutuality-based or collegial governance may be most appropriate, as with academic and professional promotions and research and teaching evaluations. The academic department, which has the expertise on disciplinary norms, frequently provides the key focal point for collegial management. For those activities for which relatively stable formal rules dominate, some form of hierarchical governance may be more appropriate. For example, in the classic bureaucratic model, there are financial rules and data privacy rules that govern expenditures and data management. Bureaucratic management in universities tends to shift its focal point from department to faculty, as faculties are simpler to centrally coordinate to promote compliance. Some researchers in higher education management have seen a significant shift from collegial to bureaucratic management as a key response to the development of mass higher education and increasing pressures of external scrutiny and demands (McCaffrey, 2018). Whilst older universities have held on to significant aspects of collegial management, newer institutions may have been established for wider public purposes such as widening access to education, delivery of more applied education and research, and are thus more liable to have started with more bureaucratic governance models from the outset.

The most significant changes to higher education in the $21^{\text {st }}$ century have been the ratcheting of competitive pressures, with competition for students in some systems, and 
competition for key employees, especially faculty. There is also increased competition for scarce research funding, and linked, but somewhat distinct, a competition for reputations generated by rankings. University leaders have responded with new forms of management sometimes described as corporate and, somewhat distinctly, entrepreneurial in approach. The corporate mode has tended to centralize power with senior management reducing the powers (and frequently numbers) of faculties. This shift has been accompanied by new technologies of governance, and in particular data and indicators. From an internal perspective data is needed to understand the extent to which strategic objectives are being met and, from an external perspective, indicators provide tools for comparing performance and instilling competition amongst both institutions and national systems. The entrepreneurial mode tries to create leaner and more devolved structures, enabling different parts of the institution to respond more rapidly to opportunities, with a lighter formal governance (and some accompanying risks for regulatory compliance).

Whilst these four modes of managing universities can be presented as a form of progression from one mode to another as institutions seek to better manage the challenges of the external environment (McCaffrey, 2018) , the approach I have laid out suggests that each may simultaneously have a role within a single institution. I further suggest that where norms are not stable and the institution needs to harness its own capacity for better understanding its problems, for securing buy-in for a wide range of actors, and for understanding and testing a range of solutions, a more reflexive mode of governance may be more appropriate. External regulation of higher education which is meta-regulatory in character, seeking to steer the self-regulatory capacity of institutions to shape their norms, practices and achievements, and to report on them, may most appropriately be met with reflexive management modes internally (Figure 1).

If it is correct to value HEI autonomy as delivering better educational and research outcomes then meta-regulatory techniques may be well calibrated to encourage HEIs to act whilst substantially retaining their autonomy, especially over matters where norms and expectations are not fixed, and likely to be substantially within the remit of universities to define as an aspect of their purpose. I hypothesize that more promising approaches to metaregulatory stimuli will develop robust and reflexive responses to the challenges of the external environment in which the organization's values and objectives can be captured not simply through high level or top down processes, but in a way that creates a living strategy shaped by and supported by the community of the HEI. Such an approach is appropriate for organizations concerned with knowledge and learning. From the perspective of a large
Managing higher education

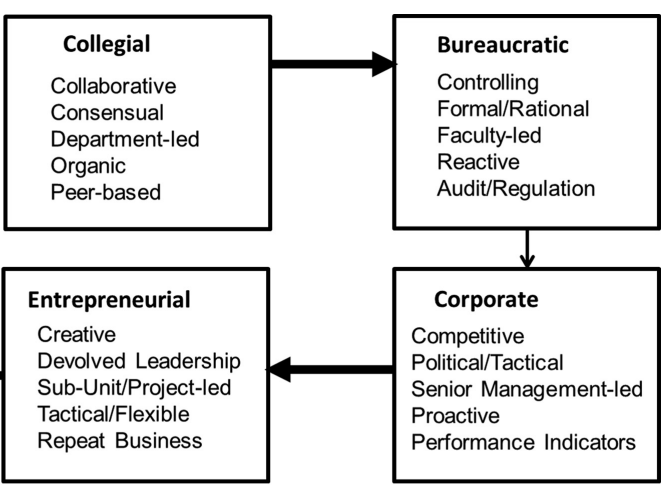

Figure 1.

HEI management style adapting to changed regulatory environment 
PAP

24,1

organization, such a reflexive approach toward understanding and responding to the environment creates a significant challenge of management and governance. Early research on organizations and institutions took universities as the model. Cohen, March and Olsen, for example, in their study of decision making in HEIs, described universities as 'organized anarchies' in which it's difficult to match problems, solutions, and contested preferences (Cohen et al., 1972). Whilst incompetence is one posture in the face of regulation, other potential responses include compliance-orientation (which may not be wholly appropriate for universities) and amoral calculation (Kagan and Scholz, 1984) or gaming (Bevan and Hood, 2006). Consequently, from the perspective of the regulator, regulatory scholars note that meta-regulation requires strong capacity to review and understand what regulatees are doing (Gilad, 2010). While this observation about capacity is based on understanding the capacity needs of hierarchy-based meta-regulators, it is likely to be equally true for competition-based meta-regulators such as research funding bodies and ranking institutions.

A reflexive approach requires universities to coordinate reflection and learning in such a way that engages internally and externally not only with what the organization does and how it does it but also with why it acts as it does. This chimes with attempts by university leaders to articulate university missions by reference to purpose and values. The reflexive approach is sometimes labelled triple-loop learning in that it encourages reflexive organizations to work back to the problems and challenges which their missions address, rather than to have those problems and challenges defined for them, which would leave them simply to work out what to do and how to do it (Parker, 2002). Such a reflexive approach to the management of the increasingly complex external environment enables universities to clearly articulate their mission and how they deliver, through engagement with their own communities, and in a way that shapes their response to regulatory and meta-regulatory pressures. It offers a counter to fatalism, recasting the university as principal, and the cast of external actors and regulators more as agents to support the delivery of a university's mission.

\section{Conclusion}

Universities present a significant puzzle and challenge for regulation, but the regulatory study of this sector also has much to offer regulatory scholarship in general. As organisations which exercise autonomy, to a greater or lesser extent in different countries, universities cannot simply be subject to hierarchical control. Regulatory scholarship and practice are, in any case, increasingly sceptical of hierarchy on its own as the basis for effective control. Within university organisations themselves the exercise of hierarchical line management is equally problematic. And yet, governments and other regulatory bodies need to be able to hold universities accountable and, indeed have a sense of steering the sector, over key aspects of public policy. These public policy aspects include education and the advancement of knowledge and further goals such as widening access to higher education and, critically, stewardship of public finances, in addition to global goals such as creating a sustainable world.

The author argues in this article that numerous examples of meta-regulation in higher education provide a means to reconcile university autonomy with the role of government and other external actors with respect to steering higher education institutions. It provides a means for universities to understand and advance the internal steering of their own purposes, faculty and staff. Meta-regulation not only steers actions, but also learning, and encourages universities and their employees to think beyond what they do and how they do it to wider purpose and values. It also shows why they perform certain actions and how they should best think about their mission and how to achieve it. Such an approach enables universities to cast external regulatory actors as agents in the delivery of university missions to at least as great an extent as universities are agents in the delivery of public policy. 


\section{References}

Bevan, G. and Hood, C. (2006), "What's measured is what matters: targets and gaming in healthcare in England”, Public Administration, Vol. 84 No. 3, pp. 517-538.

Bhopal, K. and Henderson, H. (2019), "Competing inequalities: gender versus race in higher education institutions in the UK", Educational Review, published online, doi: 10.1080/00131911.2019. 1642305.

Black, J. (2001), "Decentring regulation: the role of regulation and self-regulation in a 'Post-Regulatory' world”, Current Legal Problems, Vol. 54 No. 1, pp. 103-146.

Black, J., Boggs, A.M., Fry, H., Hillman, N., Jackson, S., King, R., .. . and Underwood, S. (2015), The Regulation of Higher Education, London School of Economics, London.

Boer, H.D. and Enders, J. (2017), "Working in the shadow of hierarchy: organisational autonomy and venues of external influence on European universities”, in Bleiklie, I., Enders, J. and Lepori, B. (Eds.), Managing Universities: Policy and Organizational Change from a Western European Comparative Perspective, Palgrave Macmillan, London, pp. 57-83.

Bowerman, M., Humphrey, C. and Owen, D. (2003), "Struggling for supremacy: the case of UK public audit institutions”, Critical Perspectives on Accounting, Vol. 14 No. 1-2, pp. 1-22.

Braithwaite, V., Braithwaite, J., Gibson, D. and Makkai, T. (2004), "Regulatory style, motivational postures and nursing home compliance”, Law and Policy, Vol. 16 No. 4, pp. 363-394.

Choudaha, R. (2017), “Three waves of international student mobility (1999-2020)”, Studies in Higher Education, Vol. 42 No. 5, pp. 825-832.

Cohen, M.D., March, J.G. and Olsen, J.P. (1972), “A garbage can model of organizational choice”, Administrative Science Quarterly, Vol. 17 No. 1, pp. 1-25.

Dill, D.D. (2011), “Governing quality”, in King, R., Marginson, S. and Naidoo, R. (Eds.), Handbook on Globalization and Higher Education, Edward Elgar, Cheltenham, pp. 438-453.

Enders, J. and Westerheijden, D.F. (2011), "The Bologna Process: from the national to the regional to the global and back", in King, R., Marginson, S. and Naidoo, R. (Eds.), Handbook on Globalization and Higher Education, Edward Elgar, Cheltenham, pp. 469-484.

Gilad, S. (2010), "It runs in the family: meta-regulation and its siblings", Regulation and Governance, Vol. 4 No. 4, pp. 485-506.

Hazelkorn, E. (2011), "Measuring world-class excellence”, in King, R., Marginson, S. and Naidoo, R. (Eds.), Handbook on Globalization and Higher Education, Edward Elgar, Cheltenham, pp. $492-515$.

Hood, C., James, O., Peters, G. and Scott, C. (2004), Controlling Modern Government: Variety, Commonality and Change, Edward Elgar, Cheltenham.

Kagan, R. and Scholz, J. (1984), “The 'Criminology of the corporation' and regulatory enforcement strategies”, in Hawkins, K. and Thomas, J. (Eds.), Enforcing Regulation, Kluwer-Nijhoff, Boston, pp. 3-27.

Lodge, M. (2018), "Regulating higher education: national audit explosions in international markets", in Cantwell, B., Coates, H. and King, R. (Eds.), Handbook on the Politics of Higher Education, Edward Elgar, Cheltenham, pp. 379-391.

Maassen, P. (2017), “The University's Governance Paradox”, Higher Education Quarterly, Vol. 71 No. 3, pp. 290-298.

Marginson, S. (2011), "Introduction to Part 1", in King, R., Marginson, S. and Naidoo, R. (Eds.), Handbook on Globalization and Higher Education, Edward Elgar, Cheltenham, pp. 3-9.

McCaffrey, P. (2018), The Higher Education Manager's Handbook (Third Ed.), Routledge, London.

OECD (2009), Higher Education to 2030, OECD, Paris.

Olssen, M. and Peters, M.A. (2005), "Neoliberalism, higher education and the knowledge economy: from the free market to knowledge capitalism”, Journal of Education Policy, Vol. 20 No. 3, pp. 313-345.
Managing higher education 
PAP

24,1

Ovseiko, P.V., Chapple, A., Edmunds, L.D. and Ziebland, S. (2017), "Advancing gender equality through the Athena SWAN Charter for Women in Science: an exploratory study of women's and men's perceptions", Health Research Policy and Systems, Vol. 15 No. 1, pp. 1-13.

Parker, C. (2002), The Open Corporation: Self-regulation and Democracy, Cambridge University Press, Melbourne.

Parker, C. and Braithwaite, J. (2003), "Regulation", in Cane, P. and Tushnet, M. (Eds.), The Oxford Handbook of Legal Studies, Oxford University Press, Oxford, pp. 119-145.

Pruvot, E.B. and Estermann, T. (2017), "The state of university autonomy in 2016”, in Pruvot, E.B. and Estermann, T., University Autonomy in Europe III: The Scorecard 2017, European Universities Association, Brussels, pp. 14-39.

Scott, C. (2008), "Reflexive governance, meta-regulation and corporate social responsibility: the Heineken Effect?", in Boeger, N., Murray, R. and Villiers, C. (Eds.), Perspectives on Corporate Social Responsibility, Edward Elgar, Cheltenham, pp. 170-185.

Scott, P. (2011), "The university as a global institution", in King, R., Marginson, S. and Naidoo, R. (Eds.), Handbook on Globalization and Higher Education, Edward Elgar, Cheltenham, pp. 59-75.

Shattock, M. (2010), Managing Successful Universities, Open University Press, Milton Keynes.

Shattock, M. (Ed.) (2008), Entrepreneurialism in Universities and the Knowledge Economy: Diversification and Organisational Change in European Higher Education, Open University Press, Milton Keynes.

Shattock, M. and Horvath, A. (2019), The Governance of British Higher Education: The Impact of Governmental, Financial and Market Pressures, Bloomsbury Academic, London.

Shore, C. and Wright, S. (2000), "Coercive accountability: the rise of audit culture in higher education", in Strathearn, M. (Ed.), Audit Cultures: Anthropological Studies in Accountability, Ethics and the Academy, Routledge, London, pp. 57-89.

\section{About the author}

Colin Scott is Professor of EU Regulation and Governance at University College Dublin where he currently serves as Vice President for Equality, Diversity and Inclusion, Dean of Social Sciences and Principal, UCD College of Social Sciences of Law, Ireland. Colin Scott can be contacted at: colin.scott@ ucd.ie

For instructions on how to order reprints of this article, please visit our website:

www.emeraldgrouppublishing.com/licensing/reprints.htm

Or contact us for further details: permissions@emeraldinsight.com 